\title{
DETECTION AND SEROTYPING OF DENGUE VIRUS CIRCULATING IN FEBRILE HUMAN SUBJECTS IN JAZAN AREA, KINGDOM OF SAUDI ARABIA
}

\author{
Abdulaziz M. Hakami ${ }^{1 *}$, Mohammed I. Qadri ${ }^{1}$, Khalid Al-Ghamdi ${ }^{1}$, Naser A. Alkenani ${ }^{1}$, \\ Zaki Monawar Eisa ${ }^{2}$, Tareq K. Khawaji ${ }^{2}$, Tariq A. Hamzi ${ }^{2}$, Marwah Bakri ${ }^{3}$ \\ ${ }^{1}$ Department of Biological Science, King Abdulaziz University, Jeddah, Saudi Arabia. \\ ${ }^{2}$ King Fahd Hospital, Jazan, Saudi Arabia. \\ ${ }^{3}$ Jazan University, Jazan, Saudi Arabia. \\ Received - August 29, 2018; Revision - September 21, 2018; Accepted - October 01, 2018 \\ Available Online - October 5, 2018 \\ DOI: http://dx.doi.org/10.18006/2018.6(5).850.861

\section{KEYWORDS} \\ Dengue virus \\ Serology \\ RT-PCR \\ ELISA \\ Serotyping \\ Saudi Arabia

\begin{abstract}
Since 1994, Saudi Arabia was reported dengue-free country, but later prodigious dissemination of the disease in various geographic locations and outbreaks have been reported. To date, dengue virus (DENV) prevailing and serotype circulating in human blood at Jazan area has limited information. The objective of the current study was to detect and serotype DENV as base data for regional epidemiology and for future control strategies. A total of 189 blood samples from acute febrile illness subjects all (age, sex and nationality) admitted to 13 hospitals at Jazan area were collected. Sera were harvested and were subjected to molecular (Reverse Transcriptase Polymerase Chain Reaction) and to serology (ELISA). The results demonstrated that, secondary DENV was more commonly detected among 25-65 age groups of patients followed by $<15$ years old patients. Primary DENV infection was mostly detected among young $(<15)$ patients and not among elderly $(>65)$ persons. Out of 189 tested samples, $44(23.3 \%)$ are infected by primary dengue infection, $79(41.8 \%)$ by secondary dengue and $66(34.9 \%)$ are dengue negative. The primary and secondary dengue infections were detected throughout the year with fluctuated prevalence with significant increase $(\mathrm{P}<0.01)$ during April month. The RT-PCR detected two serotypes (DENV-1 and DENV-2) and one confirmed concurrent mixed infection was observed in one patient. From the result of study, it can be concluded that age is a crucial variable factor in secondary DENV infectivity and in case fatality.
\end{abstract}

* Corresponding author

E-mail: ahakami@ outlook.com (Abdulaziz M. Hakami)

Peer review under responsibility of Journal of Experimental Biology and Agricultural Sciences.

Production and Hosting by Horizon Publisher India [HPI] (http://www.horizonpublisherindia.in/).

All rights reserved.
All the article published by Journal of Experimental Biology and Agricultural Sciences is licensed under a Creative Commons Attribution-NonCommercial 4.0 International License Based on a work at www.jebas.org.

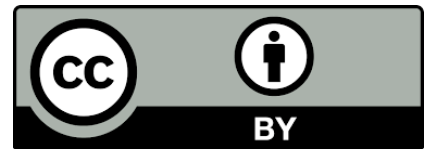




\section{Introduction}

Dengue virus (DENV) is a mosquito's borne viral disease that causes a substantial public health burden (Guzman et al., 2010). The available data suggest that at least 100 countries are endemic; 3.50 billion people are at risk, $5 \%$ case fatality rate mostly among vulnerable group (children and immunecompromised adults), 50 million positive cases were annually reported and 500,000 looks for health care facilities (Undurraga et al., 2017). The virus has four genetically distinct serotypes (de Alwis et al., 2011), clinically, causes different forms of disease complications and potentially fatal (Whitehead et al., 2007; Varatharaj, 2010). The virus is bilogically transmitted by Aedes aegypti and A. albopictus mosquitoes (Lambrechts et al., 2010). These vectors are adapted to human confinements and to related rubbish heap and building environment (Nene et al., 2007). Environmental factors (temperature, rainfall, humidity), air travel between endemic and non-endemic country (Armstrong \& Rico-Hesse, 2003), topographic societal, environmental (Chan \& Johansson, 2012), insecticides resistance (Simard et al., 2005) and impact of ecological factors (Alto \& Juliano, 2001) are responsible for increased disease incidence and sustainable transmission in many countries including Saudi Arabia. In fact, since 1994, Saudi Arabia was reported dengue-free country, but later prodigious dissemination of the disease in various geographic locations and outbreaks have been reported in Jeddah and Makkah (Ashshi, 2015; Ashshi, 2017; Organji et al., 2017). In addition, new viral stains and/or serotypes are introduced into the country through the annual displacement of pilgrims from dengue endemic regions (Azhar et al., 2015). Therefore, the disease is associated with epidemics, great economic, social impacts and public health burden on the country (Ashshi, 2017). Globally, about 75\% dengue infected cases are asymptomatic and are not detected. Therefore, differential diagnosis between dengue and non-dengue viral cause's agents is essential (Levett et al., 2000). There is no effective drug (Wiwanitkit, 2010) but the eradication surveillance; integrated vectors control, early diagnosis and prompt vaccination programme (Morrison et al., 2008). To date, the DENV prevailing and serotyping circulating in human blood at Jazan area has limited information and the available diagnostic methods based on the detection of antibodies using ELISA techniques. In fact, these antibodies are undetectable during the first week post infection, therefor; their results are subjective, especially in simultaneously mix serotypes infections. However differential diagnoses between these serotypes and/or strain is crucial without the using of molecular species-specific probes. Therefore, robust, simple, affordable and applicable laboratories detection tools for identification and differentiation between all the serotypes are highly needed. The objective of the current study was to detect and serotype dengue virus, covering some demographic features, blood constituents and disease seasonality as a base data for regional epidemiology and for future control strategies in KSA.

\section{Materials and Methods:}

\subsection{Study area}

Jazan Region, Saudi Arabia is stretching out $300 \mathrm{~km}$ along the Southern Red Sea coast, covering an area of $11,671 \mathrm{~km}^{2}$ and is populated by 1533,680 (Anonymous, 2016). The area is characterized by a distinctive hot and humid climate, inadequate sewage and waste management systems provide important sites for mosquito breeding. In addition, the area attracts large number of visitors and migrants thus increasing the dissemination of DENV in the area.

\subsection{The experimental design}

This was a hospital-based prospective study conducted for a period of 12 months (July to December 2017, January to June 2018). Febrile patients (oral or rectal temperature $>37.5^{\circ} \mathrm{C}$ or $38^{\circ} \mathrm{C}$ ) were defined (Walker et al., 1990), seeking medical care and admitted to 13 hospitals at Jazan area, Saudi Arabia were selected to curry out the current study.

\subsection{Blood samples}

By clinical officers and/or nurses, $10 \mathrm{ml}$ venous blood samples were aseptically withdrawn in blood from 189 acute febrile illness subjects (all age, sex and nationality) during their first hospital admission. Sera samples were processed by divided into two aliquots; first one cryopreserved (screw-capped cryotubes, Greiner Bio-One, Germany) for serology and molecular detection and second was kept at $-80{ }^{\circ} \mathrm{C}$ until use. The whole blood immediately was used for haematological values: Haemoglobin $(\mathrm{Hb})$ concentration, platelet and White Blood Cells (WBCs) count as baseline using automatic analyzer (ABX pentra DX 120 HORIBA ABX Magnos bc).

\subsection{Serology}

Paired sera samples were screened for DENV infection using nonstructural protein 1 (NS1), IgM and IgG-capture Enzyme-linked Immunosorbent Assay (ELISA) following the manufacturer's instructions. Fully automated ELISA (Human Diagnostics, Germany) system was used in all washing steps and the assay procedure was done following the previous protocol (Alcon et al., 2002). Briefly, the washing solution and the conjugate were respectively diluted $1 / 20$ (distilled water) and 1/50 (diluent) and were allowed to reach room temperature. To validate the assay results, reagent (R3, R4, R5) were respectively used as negative control, calibrators and positive control serum. In each microplate, 
$50 \mu \mathrm{L}$ of diluent, $50 \mu \mathrm{L}$ of samples (calibrator, controls or patients) and $100 \mu \mathrm{L}$ of diluted conjugate were added, inculpated at $37{ }^{\circ} \mathrm{C}$ for 90 minutes, washed 6 times and was gently inverted in absorbent paper. At room temperature, $160 \mu \mathrm{L}$ substrate solution was added, allowed to develop in dark for 30 minutes, $100 \mu \mathrm{L}$ of stop solution added, the plate bottom wiped, and the optical density was read at $450 \mathrm{~nm}$ using a plate reader.

\subsection{Reverse Transcriptase Polymerase Chain Reaction (RT- PCR) and conventional nested PCR}

RT-PCR and the conventional nested PCR were used as molecular confirmatory evidence for DENV infection and for serotyping.

\subsubsection{RNA isolation}

High pure viral nucleic acid kit (Roche Applied Science, Germany) was used for the extraction of RNA from all ELISA tested sera samples, following the manufacturer's protocol. Briefly, in a nuclease-free $1.5 \mathrm{ml}$ microcentrifuge tube: $200 \mu \mathrm{l}$ of binding buffer, $50 \mu 1$ Proteinase $\mathrm{K}$ and $200 \mu \mathrm{l}$ of serum sample were added, immediately mixed and were incubated for 10 minutes at $72^{\circ} \mathrm{C}$. To the mixture, $100 \mu 1$ Binding Buffer was added, $50 \mu 1$ of elution buffer was added and eluted viral RNA was kept at $-80{ }^{\circ} \mathrm{C}$ until use.

\subsubsection{Serotyping}

RT-PCR and the conventional nested PCR were performed according to the standard protocol (Lanciotti et al., 1992) with some modification. The viral RNA was amplified by first round one step RT-PCR using RT-PCR-system protocol (PromegaUSA). Briefly, in $50 \mu 1$ final volume reaction mixture, $50 \mathrm{pmol}$ (final concentration $1 \mu \mathrm{M}$ ) of each forward (D1 5'TCAATATGCTGAAACGCGCGAGAAACCG-3') and reverse (D2 5'-TTGCACCAACAGTCAATGTCTTCAGGTTC-3') primers, $5 \mu$ of RNA and nuclease free water to total volume 50 $\mu 1$ were mixed. The RT-PCR was done as follows: Incubation for 1 hour at $42^{\circ} \mathrm{C}$, initial denaturation at $\left(94^{\circ} \mathrm{C}, 3 \mathrm{~min}\right), 35$ cycle of denaturation $\left(94^{\circ} \mathrm{C}, 30\right.$ second), primers annealing $\left(55^{\circ} \mathrm{C}, 1\right.$ minute), primer extension $\left(72^{\circ} \mathrm{C}, 2\right.$ minutes $)$ and final extension for 5 minutes. Under the same thermal conditions, $1.0 \mu \mathrm{l}$ of the above PCR product (1:100 in sterile distilled water) was added as a template in the subsequent nested PCR reaction to $50 \mu \mathrm{l}$ reaction volume mixture containing forward primer D1 and type-specific (TS) reverse primers (TS1:5'-CGTCTCAGTGATCCGGGGG-3'; TS2:5'CGCCACAAGGGCCATGAACAG-3'; TS3:5'TAACATCATCATGAGACAGAGC-3' and TS4:5'CTCTGTTGTCTTAAACAAGAGA) and was further amplified by nested PCR step (second round). The PCR products amplification was analysed on gel electrophoresis (1.5 agarose in
Tris-Acetate EDTA buffer) staining with $1 \%$ ethidium bromide and the size compared with a $1 \mathrm{~Kb}$ plus DNA ladder using Gel Doc XR Imaging System (Bio-Rad).

\subsection{Statistical analysis}

Statistical package for social science (SPSS) software programme was used to analyse the collected data at significant level $(\mathrm{P}<$ 0.05 ) and the analysis of variance (ANOVA) was used for multiple comparisons of all test variables (age, gender, $\mathrm{Hb}$, platelet, WBCs counts, NS1, IgM, IgG and month) and dependent variable (dengue patient).

\subsection{Ethical approval and informed consent:}

The research proposal was reviewed and accepted by the Research Ethic Committee, King Abdulaziz University and by Ministry of Health, Saudi Arabia. Before blood samples collection, the patient, parent, or guardian provided a written informed consent.

\section{Results}

The normal blood constituents ( $\mathrm{Hb}$, platelet, WBCs counts) of all the collected samples from 189 febrile illness were analyzed by quantile-quantile (Q-Q) plot using (SPSS, software programme) and showed normal distributions pattern (Figure 1, a-c). The results of blood samples examined by different ELISA sets in different age and sex groups are shown in table (1) and the haematological constituents of positive and negative samples are shown in table (2). The pattern of NS1, IgM and IgG positive samples among different age groups and their percentages results are illustrated in figure (2). The linear results of $\operatorname{IgG}$ ELISA showed increasing pattern by age from young to elder age groups and the result of NS1 and IgM on the other hand showed different pattern, they increased from young to young adult, decreased to worth the adult and not detected in the elder age group. The blood samples collected from both sexes, $118(62.4 \%)$ male and 71 (37.6\%) female were subjected to the all different serologic tests (NS1, IgM and IgG), comparatively high positive cases were detected in male 25 (21.4\%), 35 (30.5\%), 57 (48.3\%) compare to female 1 (15.3), 20 (28.2\%), 22 (31.0\%) respectively.

\subsection{Classification of dengue virus infected cases}

The classification of clinical dengue cases as primary and secondary was based on reactivity of NS1 antigen, dengue specific immunoglobulin IgM and IgG antibody circulating in the blood. Dengue virus infected case is considered primary if the NS1 and/or IgM positive/IgG negative, likewise, the secondary if the NS1 and/or IgM negative/IgG positive (Cordeiro et al., 2009). Accordingly, DENV infected cases identification and discrimination between different primary, secondary and negative dengue suspected patients in Jazan area was carried out. 
Table 1 Distribution of dengue virus from febrile subjects' cases by ELISA in different age and sex groups

\begin{tabular}{|c|c|c|c|c|c|c|c|c|c|}
\hline \multirow{6}{*}{ 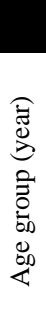 } & & \multirow[t]{2}{*}{$\mathrm{n}$} & \multirow[t]{2}{*}{$\%$} & \multicolumn{2}{|c|}{ NS1 } & \multicolumn{2}{|c|}{ IgM } & \multicolumn{2}{|c|}{$\operatorname{IgG}$} \\
\hline & & & & -ve & +ve & -ve & $+\mathrm{ve}$ & -ve & +ve \\
\hline & $<15$ & 81 & 42.9 & 75 & 6 & 60 & 21 & 55 & 26 \\
\hline & $15-24$ & 21 & 11.1 & 14 & 7 & 11 & 10 & 15 & 6 \\
\hline & $25-65$ & 81 & 42.9 & 58 & 23 & 56 & 25 & 40 & 41 \\
\hline & $>65$ & 6 & 3.1 & 6 & 0 & 6 & 0 & 0 & 6 \\
\hline & Total & 189 & 100 & 153 & 36 & 133 & 56 & 110 & 79 \\
\hline$\underset{0}{x}$ & Male & 118 & 62.4 & 92 & 25 & 82 & 36 & 61 & 57 \\
\hline$\tilde{n}$ & Female & 71 & 37.6 & 61 & 11 & 51 & 20 & 49 & 22 \\
\hline & Total & 189 & 100 & 153 & 36 & 133 & 56 & 110 & 79 \\
\hline
\end{tabular}

$N=$ number of samples, - ve $=$ negative,$+v e=$ positive
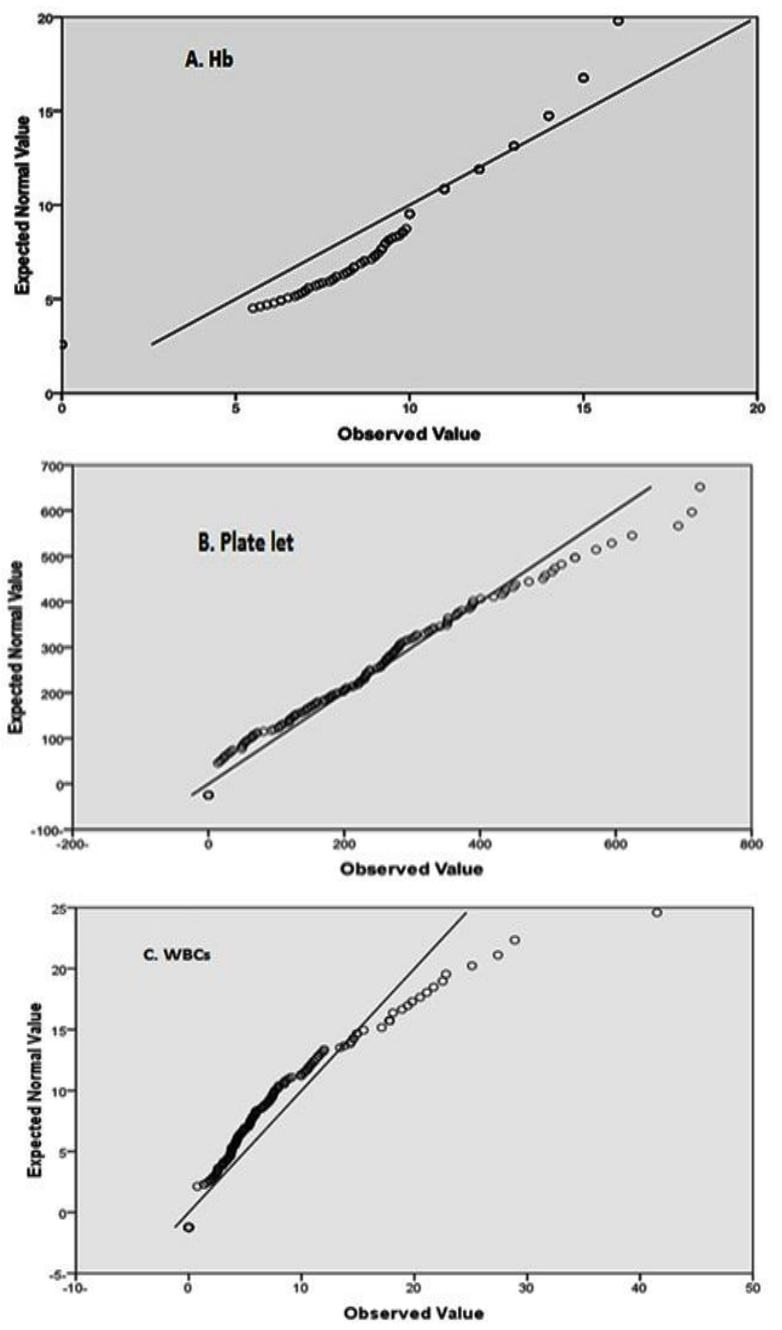

Figure 1 Normal Q-Q - Plot of (A) Hemoglobin, (B) Platelets and (C) WBCs

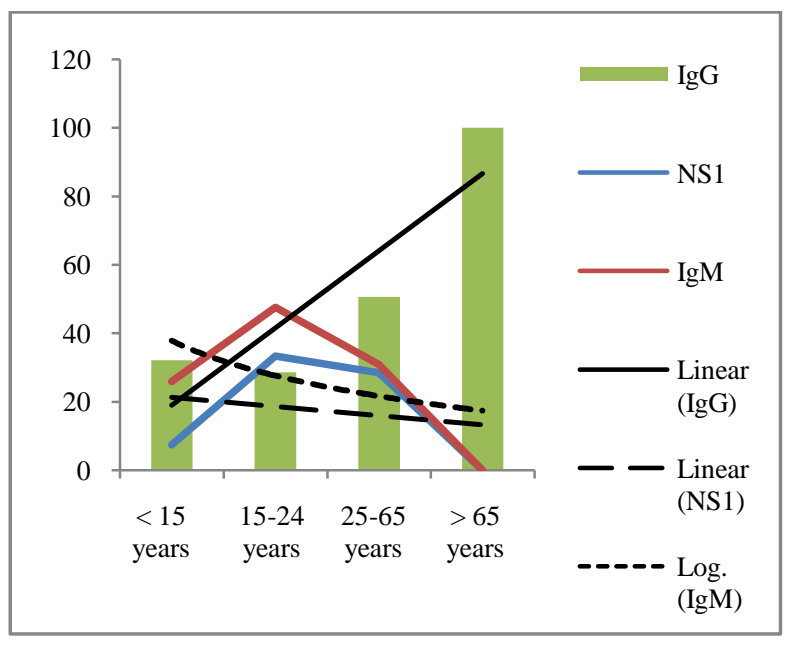

Figure 2 Pattern of percentage of the positive samples tested by NS1, IgM and IgG ELISA (Trends for IgG (-), NS1 (- -) and IgM (---) for dengue virus positive samples are indicated)

Demographic and monthly profile of dengue infected and noninfected patients are summarized in table (3) and the haematological constituents of DENV infected patients (primary and secondary) and the non-infected blood samples are shown in table (4). Secondary dengue infection was more commonly detected among 25-65 followed by $<15$ and less common in both 15-24 and > 65 years old examined patients. On the other hand, primary dengue infection was highly detected among young (< 15) and not detected among elder age group (> 65). Comparatively, male patients were highly infected by secondary $26(13.8 \%)$ and primary $57(30.2 \%)$ compare to female $18(9.5 \%)$ and $22(11.6 \%)$ respectively. On monthly bases, the primary and secondary dengue infections were detected throughout the year

Journal of Experimental Biology and Agricultural Sciences http://www.jebas.org 
Table 2 Hematological constituent in NS1, IgM and IgG positive and negative samples

\begin{tabular}{|c|c|c|c|c|c|c|c|c|c|c|c|c|}
\hline \multirow{3}{*}{ Haematological values } & \multicolumn{4}{|c|}{ NS1 } & \multicolumn{4}{|c|}{$\operatorname{IgM}$} & \multicolumn{4}{|c|}{ IgG } \\
\hline & \multicolumn{2}{|c|}{ Negative } & \multicolumn{2}{|c|}{ Positive } & \multicolumn{2}{|c|}{ Negative } & \multicolumn{2}{|c|}{ Positive } & \multicolumn{2}{|c|}{ Negative } & \multicolumn{2}{|c|}{ Positive } \\
\hline & M & $\pm \mathrm{sd}$ & M & $\pm \mathrm{sd}$ & M & $\pm \mathrm{sd}$ & M & $\pm \mathrm{sd}$ & M & $\pm \mathrm{sd}$ & M & $\pm \mathrm{sd}$ \\
\hline Haemoglobin & 10.4 & 2.5 & 13.1 & 2.2 & 10.8 & 2.6 & 11.2 & 2.7 & 11.1 & 2.6 & 10.6 & 2.7 \\
\hline Platelet & 249 & 152 & 219 & 144 & 247 & 148 & 232 & 159 & 273 & 148 & 204 & 147 \\
\hline WBCs & 9.3 & 6.8 & 5.7 & 4.3 & 9.1 & 7.0 & 7.3 & 5.3 & 8.4 & 6.8 & 8.1 & 6.6 \\
\hline
\end{tabular}

$M=$ Mean $(V / V)$, sd. $=$ standard deviation

Table 3 Classification of dengue virus infected (primary and secondary) and non-infected febrile illness cases

\begin{tabular}{|c|c|c|c|c|c|}
\hline \multirow{2}{*}{\multicolumn{2}{|c|}{ Demographic profile }} & \multicolumn{3}{|c|}{ Test } & \multirow{2}{*}{ Total (\%) } \\
\hline & & Primary n $(\%)$ & Secondary n (\%) & Negative $\mathrm{n}(\%)$ & \\
\hline \multirow{4}{*}{ 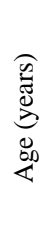 } & $<15$ & $19(10.1 \%)$ & $26(13.7)$ & 36 & $81(42.9)$ \\
\hline & $15-24$ & $9(4.8)$ & $6(3.2)$ & 6 & 21(11.1) \\
\hline & $25-65$ & $16(8.5)$ & $41(21.7)$ & 24 & $81(42.9)$ \\
\hline & $>65$ & $0(0)$ & $6(3.2)$ & 0 & $6(3.1)$ \\
\hline & Total (\%) & $44(23.3)$ & 79 (41.8) & $66(34.9)$ & $189(100)$ \\
\hline \multirow{2}{*}{ む) } & Male & $26(13.8)$ & $57(30.2)$ & 35 & $118(62.4)$ \\
\hline & Female & $18(9.5)$ & 22 (11.6) & 31 & 71(37.6) \\
\hline & Total (\%) & $44(23.3)$ & 79 (41.8) & $66(34.9)$ & $189(100)$ \\
\hline \multirow{6}{*}{ 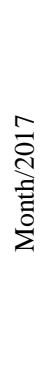 } & July & 6 & 12 & 0 & $18(9.5)$ \\
\hline & August & 1 & 3 & 0 & $4(2.1)$ \\
\hline & September & 2 & 3 & 3 & $8(4.2)$ \\
\hline & October & 3 & 4 & 17 & $24(12.7)$ \\
\hline & November & 1 & 1 & 8 & $10(5.3)$ \\
\hline & December & 0 & 4 & 4 & $8(4.2)$ \\
\hline \multirow{6}{*}{ 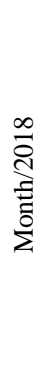 } & January & 1 & 7 & 8 & $16(8.5)$ \\
\hline & February & 7 & 5 & 4 & $16(8.5)$ \\
\hline & March & 6 & 8 & 13 & 27 (14.3) \\
\hline & April & 11 & 14 & 6 & $31(16.4)$ \\
\hline & May & 3 & 13 & 3 & $19(10.1)$ \\
\hline & June & 3 & 5 & 0 & $8(4.2)$ \\
\hline & Total (\%) & $44(23.3)$ & 79 (41.8) & 66 (34.9) & 189 (100) \\
\hline
\end{tabular}

Journal of Experimental Biology and Agricultural Sciences http://www.jebas.org 
Table 4 The correlation between negative and different course of the dengue infection in different age groups and sex

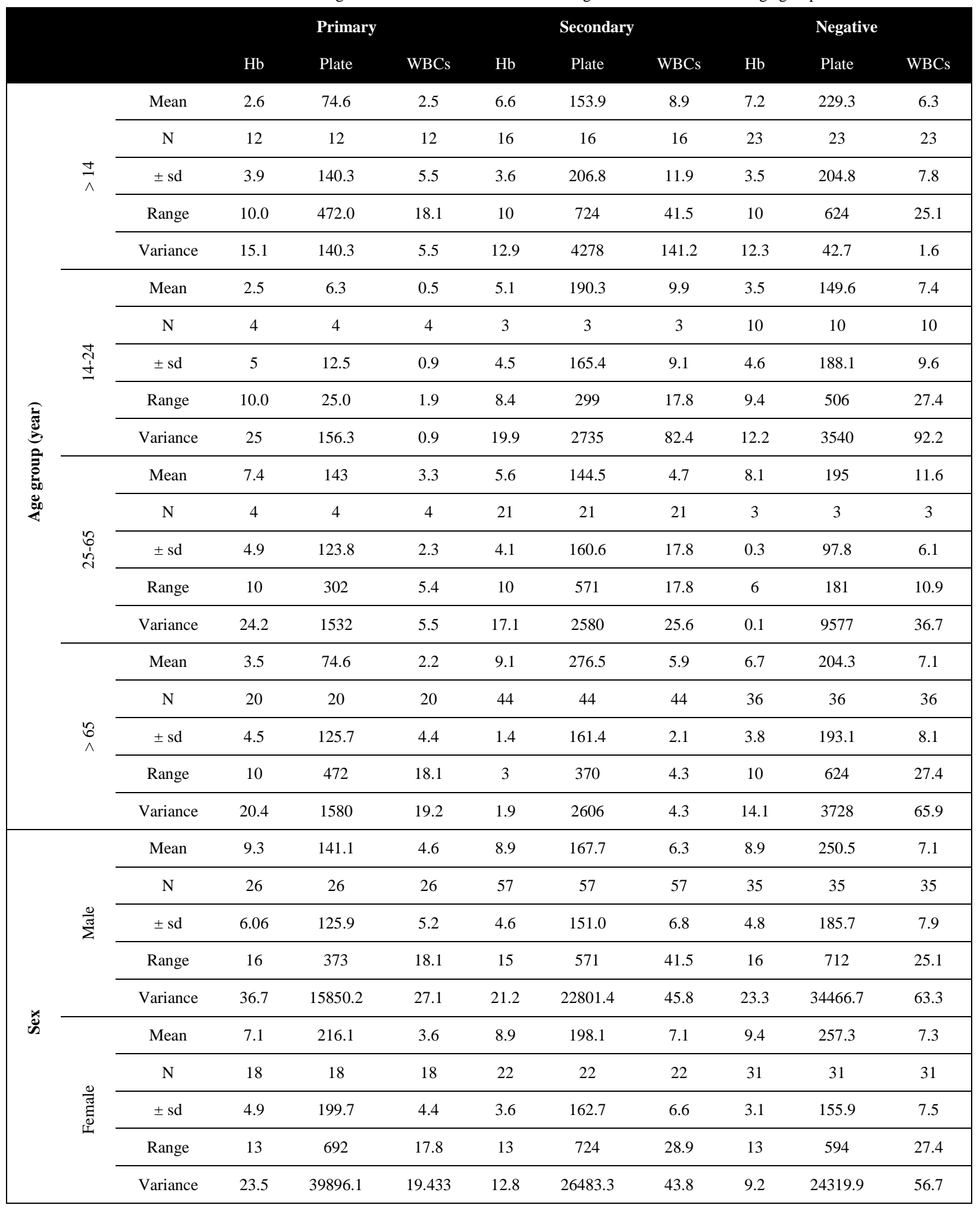

$N=$ Number, $\pm s d=$ Standard deviation

Journal of Experimental Biology and Agricultural Sciences http://www.jebas.org 


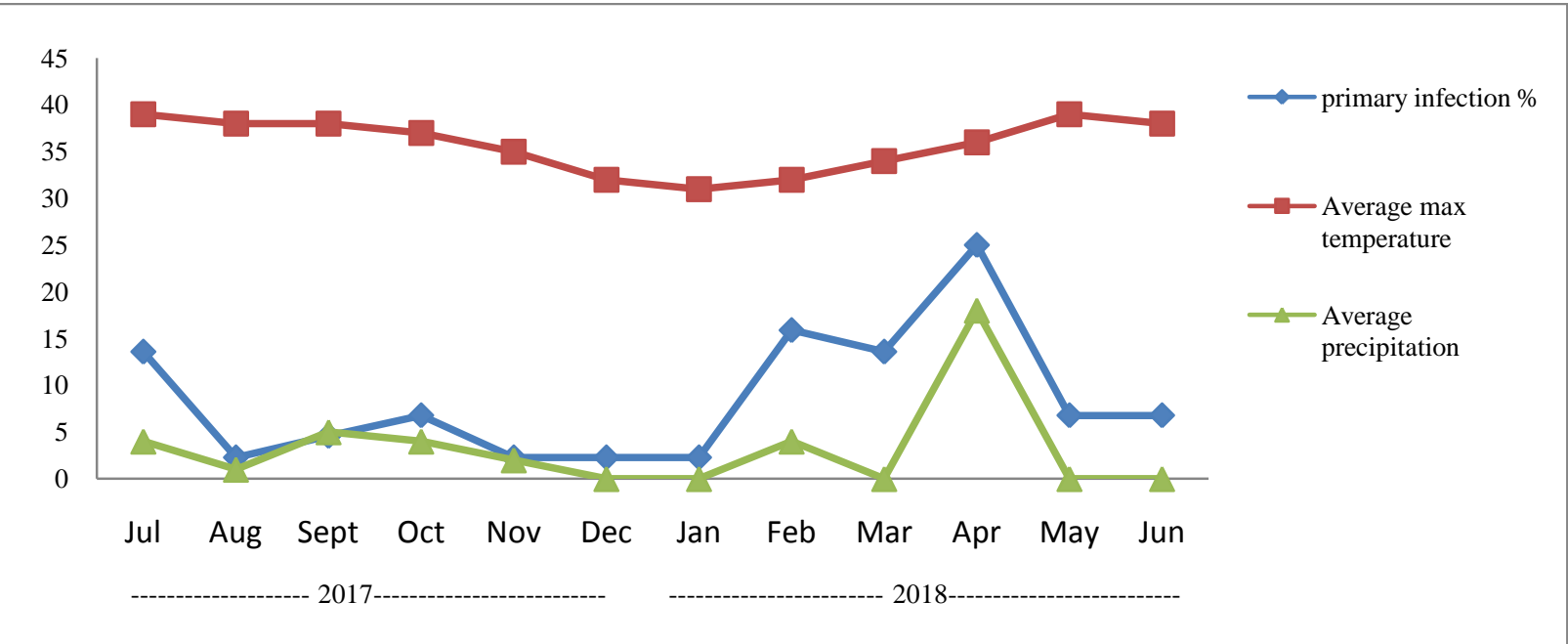

Figure 3 The correlation between the climatic factors and the prevalence of primary dengue virus infected cases

Table 5 Hematological values and laboratories results of blood samples collected from the expired cases

\begin{tabular}{|c|c|c|c|c|c|c|c|}
\hline \multicolumn{2}{|c|}{ Demographic } & \multicolumn{3}{|c|}{ Blood constituents } & \multicolumn{2}{|c|}{ DENV detection } & \multirow[t]{2}{*}{ Serotype } \\
\hline Sex & Age (year) & $\mathrm{Hb}$ & Platelets & WBCs & ELISA & PCR & \\
\hline Male & $>1$ & 13 & 66 & 4.2 & $+\mathrm{ve}$ & + ve & DENV-1 \\
\hline Male & 34 & 5.7 & 300 & 8.4 & - ve & - ve & - \\
\hline Male & 12 & 10.1 & 520 & 2.8 & - ve & - ve & - \\
\hline Male & 70 & 6.8 & 29 & 12 & $+\mathrm{ve}$ & $+\mathrm{ve}$ & DENV-2 \\
\hline Male & 11 & 9.1 & 30 & 8.9 & $+\mathrm{ve}$ & + ve & DENV-2 \\
\hline Female & $>1$ & 10.3 & 50 & 1.4 & $+\mathrm{ve}$ & + ve & DENV-1 \\
\hline Female & 14 & 8.4 & 230 & 35.9 & - ve & - ve & - \\
\hline Female & 1 & 8.4 & 27 & 17.8 & $+\mathrm{ve}$ & + ve & DENV-1 \\
\hline Female & 62 & 10.3 & 50 & 1.4 & $+\mathrm{ve}$ & + ve & DENV-1, 2 \\
\hline Female & $>1$ & 5.5 & 55 & 28.6 & $+\mathrm{ve}$ & + ve & DENV-1 \\
\hline
\end{tabular}

$+v e=$ positive,$-v e=$ negative

with fluctuated prevalence with significant increase $(\mathrm{P}<0.01)$ of infection during April/2018. The seasonality of primary dengue virus infected cases and the climate factors are illustrated in figure (3). The prevalence of the primary dengue infection during different months was significantly correlated to the rain fall precipitation.

\subsection{Mortality}

The 189 dengue suspected patients were followed-up through the study period, 10/189 (5.3\%) died during hospitalization or during treatment and their blood constituents were demonstrated in table (5). Based on the ELISA and PCR test results, 7/10 (70\%) are infected by secondary form of DENV infection, 3/10 (30\%) were non-infected (negative) and primary DENV infection were not detected in all the expired cases.

\subsection{Molecular}

Out of 189 ELISA tested sera, 123 sera samples were randomly selected maintaining the original proportion of the positive and negative ELISA tested sera and including sera from all expired 
cases, DENV RNA were extracted and further were subjected to RT-PCR and nested PCR to confirm the serology results, to calculate the sensitivity/specificity and to identify different DENV RNA serotypes.

\subsection{Sensitivity and specificity of RT-PCR}

The results of the nested PCR and NS1 ELISA were compared and the sensitivity and the specificity of the nested PCR technique were calculated following the previous formula (Salih et al., 2012). More or less, similar results were seen using both test techniques and respectively agreed on 60 and 58 positive and negative samples. Comparatively, the specificity and the sensitivity of nested PCR technique were respectively calculated $96.8 \%$ and $95.1 \%$.

\subsection{DENV RNA detection and serotyping}

The results of $1.5 \%$ agarose electrophoresis analysis of RT-PCR and nested PCR products were demonstrated in figure (4). DENV1 and DENV-2 were detected in all blood samples collected from the study area throughout the 12 months. Only one patient had confirmed concurrent mixed infection with DENV serotype 1 and serotype 2 .

\section{Discussion}

Total of 189 serum samples were collected on the day where the dengue suspected patients presented to 13 hospitals outpatient clinics at Jazan area during 12 months (June to December 2017,

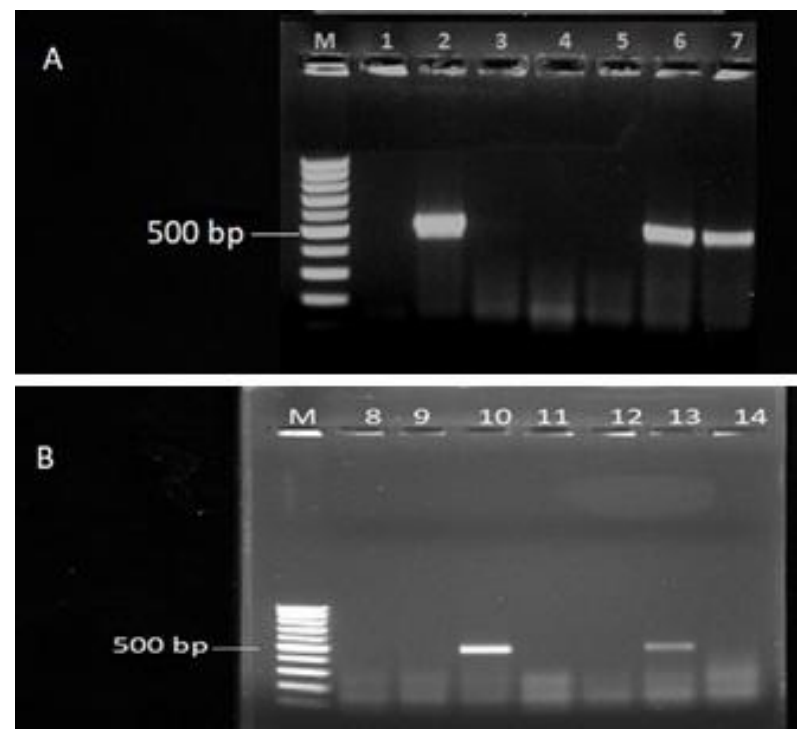

Figure 4 Documentations of dengue virus by RT-PCR using dengue virus specific primer sets. Lane ${ }_{M}$, standard size marker, $L_{1}$ negative control, $\mathrm{L}_{2}$ positive control, $\mathrm{L}_{3-14}$ test samples
January to July) and were subjected to dengue antibodies detection by different serological test using NS1, IgG and IgM ELISA. The results of tested blood samples were correlated with some demographic factors (age, gender), month and blood constituents. The blood constituents $(\mathrm{Hb}$, platelets and WBCs count) in different course of dengue infected and uninfected patients using NS1, IgM and IgG ELISA were demonstrated. The NS1, IgM and IgG ELISA, the blood platelets and WBCs count were significantly reduced in dengue infected compare to noninfected patients; on the other hand, $\mathrm{Hb}$ is slightly changed. These results are concordance with other findings (Lin et al., 1989; Ho et al., 2013; Kotepui et al., 2017). The blood samples were collected from different age groups range between 6 months and 83 years old and are categorized into 4 age groups (Anonymous, 2007). Accordingly, the young ( $<15$ years) and adults $(25-65$ years) were counted for largest age groups $81(42.9 \%)$ and the young adult (15-24 years) and the elder (> 65 years) were counted 21 $(11.1 \%)$ and $6(3.1 \%)$ respectively. The linear results of $\operatorname{IgG}$ IELISA showed increasing pattern by age from young to elder age groups and the result of NS1 and IgM on the other hand showed different pattern, they increased from young to young adult, decreased to worth the adult and not detected by in the elder age group. Worldwide, humans of all age groups are at risk to dengue infection; especially it poses a paediatric public health problem in some parts of the world (Gubler, 1998). On the other hand, there is a clear distinction between young and elders in the pattern of dengue complications and association, and this variation partially depend on intrinsic age-dependent and physiological differences (Dinh et al., 2012). Knowledge of such differences is important to inform research on disease pathogenesis, as well as to encourage development of management guidelines that are appropriate to the age-groups at risk. In general, the results of ELISA detecting DENV infection during the present study and the comparison between the different age groups revealed that, adults were infected disproportionately to children. In fact, the detections of the NS1 antigen and dengue related $\operatorname{IgM}$ and $\operatorname{IgG}$ antibodies are commonly used in dengue diagnoses (Khurram et al., 2014; Khandia et al., 2018), NS1 is virus-specific non-structural protein that can be detected for up to 9 days after dengue infection (Alcon et al., 2002; Lebani et al., 2017), IgM antibodies become detectable in most patients at days 3-5 of fever onset (Khurram et al., 2014). Related to IgG antibodies detected (past infection), the most susceptible age group for dengue infection was older than 65 years and followed by 25-65 years. This finding is concordance the recent dengue prediction by IgG sero-prevalence (Jamjoom et al., 2016). Therefore, it can be suggested that the individuals in these age groups were actively involved in outdoor activities that increased their chances of exposure to the infective dengue vector bite, the $\operatorname{IgG}$ antibodies are circulated in the elder blood and give solid immunity for long time. Similar observations have been reported from South East Asia regions where adults were

Journal of Experimental Biology and Agricultural Sciences http://www.jebas.org 
more affected than children (Tank \& Jain, 2012) and in Saudi Arabia (Khormi \& Kumar, 2011). Other possible explanation is the preponderance of patients in this study seeking for clinical care several days after the onset of illness, favouring the detection of $\mathrm{IgG}$, which circulates in the serum for longer periods than viral the detected by NS1 (Zangmo et al., 2015). In NS1 and IgM, the high infection was detected in 25-65 and less in young groups and no infection in elder age groups. Regarding children, a lower dengue infection was observed in age group $(<14$ years old) and in young adults (15-24 years). A. aegypti vector is considered a predominantly day biting outdoor DEN V vector, children and young adults were at a lower risk of dengue infection as they spend most of their time indoors, completely covered or sleep under bed nets unlike the adults (25-65 years) who were able to play and spend more time outdoors within and around the residential areas and elder (older than 65) are immune. Similar findings were observed from southeast India and Caribbean (Akram el at. 1998; Kumar et al., 2013). Although, young aged individuals less than 15 years old, were immune because of maternal antibody enhancement of disease, as maternal antibodies wanes from protective to enhancing levels (Halstead, 2002; Hammond et al., 2005). The result of dengue positive and negative cases in different sex was correlated. The blood samples collected from both sexes, $118(62.4 \%)$ male and 71 (37.6\%) female were tested by NS1, IgM and IgG, comparatively, high positive cases were detected in male 25 (21.4\%), 35 (30.5\%), 57 (48.3\%) as compared to female 1 (15.3), 20 (28.2\%), 22 (31.0\%) in all different serologic test NS1, IgM and IgG respectively. Gender differences in dengue infection have been inconsistent worldwide, while some studies reporting a higher prevalence in men (Yew et al., 2009; Anker \& Arima, 2011), others have shown a higher prevalence in women (Morrison et al., 1998) and others reported no gender difference (Kalayanarooj \& Nimmannitya, 2000). The present study indicates those males are highly susceptible to the dengue infection. The current findings are agreed with the recent investigation carried out in Saudi Arabia by Jamjoom et al. (2016) and not in harmony with that from Nigeria and Madagascar (Sissoko et al., 2010; Dawurung et al., 2010). Therefore, the present findings could state that men in Jazan area a r e energetic, carrying out domestic activities during the day and women may less exposed to mosquito bites ad their body are covered compare to the men or could be genetically different. The findings of the present study were similar to other studies from India which suggested that exposure to multiple serotypes over a period resulted in development of diverse immunity (Sharma et al., 2012; Tomashek et al., 2009). There has been a growing recognition that biological differences between males and females based on genetic, immunological, and hormonal factors may determine the susceptibility to dengue infection (WHO, 2007). Our results concerning the gender differences related to infection due to dengue virus (Hakim et al.,
2011). The classification of dengue infected cases to primary and secondary and non-infected in different age, sex and groups, months and haematological values were conducted and assisted. The immune response varies in case of primary infection (first infection) or secondary. A primary infection is characterized by a slow and low response in antibody levels. The IgM antibody appears first while the immunoglobulin $\mathrm{IgG}$ is detected at the end of the first week of the disease and its rate increases slowly. IgM can remain elevated in serum for two to three months after the illness. During a secondary infection, antibody titres increase very quickly with high levels of IgG detected even in the acute phase. The four dengue virus serotypes can co-circulate in the endemic areas because the immunity to one serotype does not afford protection from the infection by a heterotopous serotype. Individual variations occur in antibody responses to the dengue virus. Secondary infections are associated with elevated risks of severe disease outcomes. Primary and secondary infections are distinguishable based on their antibody responses. On monthly bases, the primary and secondary dengue infections were detected throughout the year with fluctuated prevalence with significant increase $(\mathrm{P}<0.01)$ of infection during April/2018. The seasonality of primary dengue virus infected cases and the climate factors are illustrated in figure (3). The prevalence of the primary dengue infection during different months was significantly correlated to the rain fall precipitation and high peak during April. Similar finding from Saudi Arabia, Pakistan and from Bangladesh (Ahmed et al., 2008; Siddiqui et al., 2009; Muraduzzaman et al., 2018) agreed with the current study. On the other hand, however, other studies have shown that dengue cases coincided mainly with the post monsoon period of subnormal rainfall. This was because of the relatively high prevalence and distribution of A. aegypti larval indices after post monsoon rains (Baba \& Talle, 2011; Pun et al., 2011). Occurrence of dengue infection in the present study appeared to be independent of temperature; this could be due to the fact that the temperature in Jazan throughout the year is high and not heterogeneous. We could propose that all climatic factors, the inadequate public services, ecological factors, and ineffective vector control are collectively contributing in dissemination and could play a role to dengue sustainability in Jazan area. Most of epidemiological studies used mathematical models that developed to predict dengue seasonality (Bartley et al., 2002; Nakhapakorn \& Tripathi, 2005). About three fourth of the expired cases during hospitalization or during treatment were infected by secondary dengue infection and one fourth were negatively tested to DENV infection. The correlation between nested PCR and ELISA using NS1 results were more or less, similar and comparatively, the specificity and the sensitivity of nested PCR technique were respectively calculated $96.8 \%$ and $95.1 \%$. DENV RNA detection and serotyping revealed two serotypes (DENV-1 and DENV-2) circulating in all blood samples collected from febrile illness 
subject in the study area throughout the 12 months. Only one patient had confirmed concurrent mixed infection with DENV serotype 1 and serotype 2. Our result indicated that, age is a crucial variable factor in secondary DEN-2 infectivity and the case fatality. Since, during secondary DEN-2 infection, the high fatality rate in (young infant and/or elderly) is reported (Guzmán et al., 2002).

\section{Conclusion}

Age is a crucial variable factor in secondary DENV infectivity and in case fatality. Overall, the increased transmission of dengue coincided with the rainfall. All climatic factors, the inadequate public services, ecological factors, and ineffective vector control could play a role in the disease sustainability in Jazan area.

\section{Acknowledgements}

A.M. Hakami and M.I. Qadri are supported by King Abdulaziz City for Science and Technology (KACST). The authors acknowledge the Microbiology Department, Central Laboratory, King Fahd Hospital, Jazan, Saudi Arabia for technical assistance and molecular laboratories facilities.

\section{Competing interests}

The authors declare no competing interests and contribute equally.

\section{References}

Ahmed S, Arif F, Yahya Y, Rehman A, Abbas K, Ashraf S ( 2008) Dengue fever outbreak in Karachi: A study profile and outcome of children under 15 year of age. Journal of the Pakistan Medical Association 58: 4-8.

Akram DS, Igarashi A, Takasu T (1998) Dengue virus infection among children with undifferentiated fever in Karachi. Indian Journal of Pediatrics 65: 735-740.

Alcon S, Talarmin A, Debruyne M, Falconar A, Deubel V, Flamand M (2002) Enzyme-linked immunosorbent assay specific to Dengue virus type 1 nonstructural protein NS1 reveals circulation of the antigen in the blood during the acute phase of disease in patients experiencing primary or secondary infections. Journal of Clinical Microbiology 40: 376-381.

Alto BW, Juliano SA (2001) Precipitation and temperature effects on populations of Aedes albopictus (Diptera: Culicidae): implications for range expansion. Journal of Medical Entomology 38: 646-656.

Anker M, Arima Y (2011) Male-female differences in the number of reported incident dengue fever cases in six Asian countries. Western Pacific Surveillance and Response Journal 2: 17-23.
Anonymous (2007) Age Categories Life Cycle Groupings, Statistics Canada.

Anonymous (2016) General Authority for Statistics. Saudi Arabia, Jazan, Jazan Governmental Press.

Armstrong PM, Rico-Hesse R (2003) Efficiency of dengue serotype 2 virus strains to infect and disseminate in Aedes aegypti. American Journal of Tropical Medicine and Hygiene 68: 539-544.

Ashshi AM (2015) Serodetection of Dengue virus and its antibodies among blood donors in the western region of Saudi Arabia: a preliminary study. Blood Transfusion 13: 135-138.

Ashshi AM (2017) The prevalence of dengue virus serotypes in asymptomatic blood donors reveals the emergence of serotype 4 in Saudi Arabia. Virology Journal 14: 107-114.

Azhar EI, Hashem AM, El-Kafrawy SA, Abol-Ela S, Abd-Alla AM, Sohrab SS, Madani TA (2015) Complete genome sequencing and phylogenetic analysis of dengue type 1 virus isolated from Jeddah, Saudi Arabia. Virology Journal 12: 1-11.

Baba MM, Talle M (2011) The effect of climate on dengue virus infections in Nigeria. New York Science Journal 4: 28-33.

Bartley LM, Donnelly CA, Garnett GP (2002) The seasonal pattern of dengue in endemic areas: mathematical models of mechanisms. Transactions of the Royal Society of Tropical Medicine and Hygiene 96: 387-397.

Chan M, Johansson MA (2012) The incubation periods of dengue viruses. PloS one 7: e50972.

Cordeiro MT, Braga-Neto U, Nogueira RMR, Marques ET (2009) Reliable classifier to differentiate primary and secondary acute dengue infection based on IgG ELISA. PloS One 4: e4945.

Dawurung JS, Baba MM, Stephen G, Jonas SC, Bukbuk DN, Dawurung CJ (2010) Serological evidence of acute dengue virus infection among febrile patients attending Plateau State Specialist Hospital Jos, Nigeria. Report and Opinion 2: 71-76.

De Alwis R, Beltramello M, Messer WB, Sukupolvi-Petty S, Wahala WM, Kraus A, Wang WK (2011) In-depth analysis of the antibody response of individuals exposed to primary dengue virus infection. PLoS Neglected Tropical Diseases 5: e1188.

Dinh T, Le Thi Thu T, Nguyen Minh D, Tran Van N, Tran Tinh H, Nguyen Van Vinh C (2012) Clinical Features of Dengue in a Large Vietnamese Cohort: Intrinsically Lower Platelet Counts and Greater Risk for Bleeding in Adults than Children. PLoS Neglected Tropical Diseases 6: e1679. 
Gubler DJ (1998) Dengue and dengue hemorrhagic fever. Clinical Microbiology Reviews 11: 480-496.

Guzman MG, Halstead SB, Artsob H, Buchy P, Farrar J, Gubler DJ, Nathan MB (2010) Dengue: a continuing global threat. Nature Reviews Microbiology 8: S7-S16.

Guzmán MG, Kouri G, Bravo J, Valdes L, Susana V, Halstead SB (2002) Effect of age on outcome of secondary dengue 2 infections. International Journal of Infectious Diseases 6: 118-124.

Hakim ST, Tayyab SM, Qasmi SU, Nadeem SG (2011) An experience with dengue in Pakistan: An expanding problem. Ibnosina Journal of Medicine and Biomedical Sciences 3: 3-8.

Halstead SB (2002) Dengue. Current Opinion in Infectious Diseases 15: 471-476.

Hammond SN, Balmaseda A, Perez L, Tellez Y, Saborio SI, Mercado JC (2005) Differences in dengue severity in infants, children, and adults in a 3-year hospital-based study in Nicaragua. American Journal of Tropical Medicine and Hygiene 73:1063-1070.

Ho TS, Wang SM, Lin YS, Liu CC (2013) Clinical and laboratory predictive markers for acute dengue infection. Journal of Biomedical Science 20: 75-82.

Jamjoom GA, Azhar EI, Kao MA, Radadi RM (2016) Seroepidemiology of asymptomatic dengue virus infection in Jeddah, Saudi Arabia. Virology Research and Treatment 7: 1-7.

Kalayanarooj S, Nimmannitya S (2000) Clinical and laboratory presentations of dengue patients with different serotypes. Dengue Bulletin 24: 53-59.

Khandia R, Munjal A, Dhama K, Karthik K, Tiwari R, Malik YS, Chaicumpa W (2018) Modulation of Dengue/Zika virus Pathogenicity by Antibody-Dependent enhancement and Strategies to Protect Against enhancement in Zika virus infection. Frontiers in immunology 9: 00597.

Khormi HM, Kumar L (2011) Modeling dengue fever risk based on socioeconomic parameters, nationality and age groups: GIS and remote sensing based case study. Science of the Total Environment 409: 4713-4719.

Khurram M, Qayyum W, ul Hassan SJ, Mumtaz S, Bushra HT, Umar M (2014) Dengue hemorrhagic fever: comparison of patients with primary and secondary infections. Journal of Infection and Public Health 7: 489-495.

Kotepui M, PhunPhuech B, Phiwklam N, Uthaisar K (2017) Differentiating between dengue fever and malaria using hematological parameters in endemic areas of Thailand. Infectious Diseases of Poverty 6: 27-35.

Kumar A, Hilaire MG, Nielsen AL (2013) Epidemiological trends and clinical manifestations of Dengue among children in one of the English-speaking Caribbean countries. Transactions of the Royal Society of Tropical Medicine and Hygiene 107: 254-260.

Lambrechts L, Scott TW, Gubler DJ (2010) Consequences of the expanding global distribution of Aedes albopictus for dengue virus transmission. PLoS Neglected Tropical Diseases 4: e646.

Lanciotti RS, Calisher CH, Gubler DJ, Chang GJ, Vorndam AV (1992) Rapid detection and typing of dengue viruses from clinical samples by using reverse transcriptase-polymerase chain reaction. Journal of Clinical Microbiology 30: 545-551.

Lebani K, Jones ML, Watterson D, Ranzoni A, Traves RJ, Young PR, Mahler S M (2017) Isolation of serotype-specific antibodies against dengue virus non-structural protein 1 using phage display and application in a multiplexed serotyping assay. PloS One 12: e0180669.

Levett PN, Branch SL, Edwards CN (2000) Detection of dengue infection in patients investigated for leptospirosis in Barbados. The American Journal of Tropical Medicine and Hygiene 62: 112-114.

Lin SF, Liu HW, Chang CS, Yen JH, Chen TP (1989) Hematological aspects of dengue fever. Gaoxiong yi xue ke xue za zhi. The Kaohsiung Journal of Medical Sciences 5: 12-16.

Morrison AC, Getis A, Santiago M, Rigau-Perez JG, Reiter P (1998) Exploratory space-time analysis of reported dengue cases during an outbreak in Florida, Puerto Rico, 1991-1992. The American Journal of Tropical Medicine and Hygiene 58: 287-298.

Morrison AC, Zielinski-Gutierrez E, Scott TW, Rosenberg R (2008) Defining challenges and proposing solutions for control of the virus vector Aedes aegypti. PLoS Medicine 5: e68.

Muraduzzaman AKM, Alam AN, Sultana S, Siddiqua M, Khan MH, Akram A, Shirin T (2018) Circulating dengue virus serotypes in Bangladesh from 2013 to 2016. Virus Disease 29: 303-307.

Nakhapakorn K, Tripathi NK (2005) An information value based analysis of physical and climatic factors affecting dengue fever and dengue haemorrhagic fever incidence. International Journal of Health Geographic 4: 13-25.

Nene V, Wortman JR, Lawson D, Haas B, Kodira C, Tu ZJ, Loftus B, Xi Z, Megy K, Grabherr M, Ren Q, Zdobnov EM, 
Lobo NF, Campbell KS, Brown SE, Bonaldo MF, Zhu J, Sinkins SP, Hogenkamp DG, Amedeo P, Arensburger P, Atkinson PW, Bidwell S, Biedler J, Birney E, Bruggner RV, Costas J, Coy MR, Crabtree J, Crawford M, Debruyn B, Decaprio D, Eiglmeier K, Eisenstadt E, El-Dorry H, Gelbart WM, Gomes SL, Hammond M, Hannick LI, Hogan JR, Holmes MH, Jaffe D, Johnston JS, Kennedy RC, Koo H, Kravitz S, Kriventseva EV, Kulp D, Labutti K, Lee E, Li S, Lovin DD, Mao C, Mauceli E, Menck CF, Miller JR, Montgomery P, Mori A, Nascimento AL, Naveira HF, Nusbaum C, O'leary S, Orvis J, Pertea M, Quesneville H, Reidenbach KR, Rogers YH, Roth CW, Schneider JR, Schatz M, Shumway M, Stanke M, Stinson EO, Tubio JM, Vanzee JP, Verjovski-Almeida S, Werner D, White O, Wyder S, Zeng Q, Zhao Q, Zhao Y, Hill CA, Raikhel AS, Soares MB, Knudson DL, Lee NH, Galagan J, Salzberg SL, Paulsen IT, Dimopoulos G, Collins FH, Birren B, Fraser-Liggett CM, Severson DW (2007) Genome sequence of Aedes aegypti, a major arbovirus vector. Science $316: 1718-1723$.

Organji SR, Abulreesh HH, Osman GE (2017) Circulation of dengue virus serotypes in the city of Makkah, Saudi Arabia, as determined by reverse transcription polymerase chain reaction. Canadian Journal of Infectious Diseases and Medical Microbiology 16: 5-9.

Pun R, Pant KP, Bhatta DR, Pandey BD (2011) Acute Dengue Infection in the WesternTerai Region of Nepal. Journal of Nepal Medical Association 51: 11-14.

Salih DA, Ali AM, Liu Z, Bakheit MA, Taha KM, El Imam AH, Kullmann B, El Hussein AM, Ahmed JS, Seitzer U (2012) Development of a loop-mediated isothermal amplification method for detection of Theileria lestoquardi. Parasitology Research 110: 533-538.

Sharma Y, Kaur M, Singh S, Pant L, Kudesia M, Jain S (2012) Seroprevalence and trend of dengue cases admitted to a government hospital, Delhi - 5-year study (2006-2010): A look into the age shift. International Journal of Preventive Medicine 3: 537-543.

Siddiqui FJ, Haider SR, Bhutta ZA (2009) Endemic Dengue Fever: a seldom recognized hazard for Pakistani children. The Journal of Infection in Developing Countries 3: 306-312.

Simard F, Nchoutpouen E, Toto JC, Fontenille D (2005) Geographic distribution and breeding site preference of Aedes albopictus and Aedes aegypti (Diptera: Culicidae) in Cameroon, Central Africa. Journal of Medical Entomology 42: 726-731.
Sissoko D, Ezzedine K, Giry C, Moendandze A, Lernout T, D’Ortenzio E, Pettinelli F, Malvy D (2010) Seroepidemiology of Dengue Virus in Mayotte, Indian Ocean, 2006. PLoS ONE 5: e14141.

Tank AG, Jain MR (2012) Trend of dengue in a tertiary care hospital of Surat City, western india. National Journal of Community Medicine 3: 302-304.

Tomashek KM, Rivera A, Muñoz-Jordan JL, Hunsperger E, Santiago L, Padro O, Garcia E, Wellington S (2009) Description of a large island-wide outbreak of dengue in Puerto Rico, 2007. The American journal of tropical medicine and hygiene 81: 467474.

Undurraga EA, Edillo FE, Erasmo JNV, Alera MTP, Yoon IK, Largo FM; Shepard DS (2017) Disease Burden of Dengue in the Philippines: Adjusting for Underreporting by Comparing Active and Passive Dengue Surveillance in Punta Princesa, Cebu City. The American Journal of Tropical Medicine and Hygiene, 96: 887-898.

Varatharaj A (2010) Encephalitis in the clinical spectrum of dengue infection. Neurology India 58: 585-591.

Walker HK, Hall WD, Hurst JW (1990) Clinical Methods: The History. Physical, and Laboratory Examinations, (Ed). Boston, Butterworth-Heinemann, Pp.60.

Whitehead SS, Blaney JE, Durbin AP, Murphy BR (2007) Prospects for a dengue virus vaccine. Nature Reviews Microbiology 5: 518-528.

WHO (2007) Addressing sex and gender in epidemic-prone infectious diseases. WHO, Geneva, Switzerland 1-46.

Wiwanitkit V (2010) Dengue fever: diagnosis and treatment. Expert Review of Anti-infective Therapy 8: 841-845.

Yew YW, Ye T, Ang LW, Ng LC, Yap G, James L, Goh KT (2009) Seroepidemiology of dengue virus infection among adults in Singapore. Annals, Academy of Medicine, Singapore 38: 667-675.

Zangmo S, Klungthong C, Chinnawirotpisan P, Tantimavanich S, Kosoltanapiwat N, Thaisomboonsuk B, Fernandez S (2015) Epidemiological and molecular characterization of dengue virus circulating in Bhutan, 2013-2014. PLoS Neglected Tropical Diseases, 9: e0004010. 